\title{
The Trade-off Between Income Inequality and Carbon Dioxide Emissions
}

\author{
Nicole Grunewald, Stephan Klasen, \\ Inmaculada Martínez-Zarzoso, and Chris Muris*
}

This version: January 12, 2015.

\begin{abstract}
Based on a substantially larger data set (in both regional and temporal coverage) than the existing literature, we investigate the theoretically ambiguous link between income inequality and per capita emissions using cross-country panel data. We find that the relationship depends on the level of income. Using an arguably superior group-fixed effects estimator, we show that for low and middle-income economies, higher income inequality is associated with lower carbon emissions while in upper middle-income and high-income economies, higher income inequality increases per capita emissions. The result is robust to the inclusion of plausible transmission variables as well as different data sources or aggregations.
\end{abstract}

JEL codes: Q0, Q1, Q3

Keywords: Environmental quality, income inequality, panel data.

\section{Introduction}

Global poverty and climate change are two major challenges facing mankind in the twenty-first century. Economic growth leads to absolute poverty reduction, particularly if it is not associated

*Grunewald, Klasen, Martinez-Zarzoso: University of Goettingen. Martinze-Zarzoso: University Jaume I. Muris: Simon Fraser University. 
with rising income inequality (e.g. Dollar and Kraay, 2002; Bourguignon, 2003). There is a substantial literature that investigates the relationship between income and carbon dioxide emissions, the greenhouse effect is primarily responsible for the increase in global surface temperature. This literature suggests that economic growth, at least up to a certain level of economic development, increases greenhouse gases (IPCC, 2014; Steckel et al., 2014). Consequently, from the perspective of a developing country, economic growth may alleviate poverty, but intensify climate problems. A related issue is whether there is also a tradeoff between income inequality and global warming, as stated by Ravallion et al. (2000). As we discuss below, the theoretical and empirical literature generates mixed results on this question, pointing to different mechanisms and effects. Much of this literature is, however, based on rather simple econometric methods and older data on both inequality as well as emissions. We improve upon the existing literature in both of these respects.

A particular econometric innovation with respect to the existing literature is that we use a group fixed effects estimator (Bonhomme and Manresa, 2015) as opposed to a standard fixed effects estimator. This grouped fixed effects estimator takes into account that different regions of the world adopt clean technologies at different rates. Furthermore, the estimator arguable deals better with endogeneity due to unobserved heterogeneity. Finally, the within transformation associated with the fixed effects estimator would eliminate the relatively small intertemporal variation that exists in the Gini data (see the literature on the debates on inequality and growth literature, e.g. Forbes, 2000, and Banerjee and Duflo, 2003).

To the best of our knowledge, only three papers are closely related to our empirical investigation of the link between per capita carbon dioxide emissions, per capita output, and inequality. Ravallion et al. (2000) use a pooled OLS model that interacts inequality with a third-order polynomial of income, a time trend, and population size. The panel data set consists of 42 countries over the period from 1975 to 1992. The authors use one (average) inequality measure per country. They find that there is a static tradeoff between reducing carbon emissions and reducing income inequality. Borghesi (2006) applies OLS and fixed effects panel data estimators to a panel data set of 37 countries for the period 1988 to 1995. He prefers the fixed effects estimator and finds that inequality does not have an effect on emissions. For the pooled OLS estimator, he finds a 
statistically significant negative effect between income inequality and carbon dioxide emissions. Heerink et al. (2001) use a cross-section design with 65 country observations from about 1985 . The specification includes income, its square, and the Gini coefficient. Similar to Ravallion et al (2000), they find that income inequality is negatively associaed with carbon emissions per capita. All three studies rely on the inequality measure from the data set described in Deininger and Squire (1996). Our analysis uses expanded and improved data from Solt (2009), which is derived from the much broader, more consistent, and more reliable WIDER World Income Inequality Database. This allows us to use a larger set of countries (158 instead of 65 resp. 37) and observations from 1980 up to 2008, compared to 1975-1992 and 1988-1995 in the existing studies. Furthermore, we argue that cross-section estimates based on pooled OLS are arguably not the most appropriate tools for this analysis, and favor the grouped fixed effects estimator. We also compare our analysis also to a standard fixed effects estimator. ${ }^{1}$

We find that the relationship between income inequality and emissions depends on income levels. At lower levels of incomes higher income inequality reduces emissions while at higher levels of income, the effect is reverse. The group fixed effects also generate interesting differentiated time trends linked closely to trends in energy intensity in the different groups.

The rest of the paper is structured as follows. Section 2 reviews theoretical arguments in the existing literature, emphasizing that the relationship between income inequality and emissions is ambiguous. Section 3 describes the panel data set. Section 4 outlines the fixed effects model for our setting, and reveals its shortcoming in the current context. We then argue that a group fixed effects estimator is more appropriate, and describe that model. The main results and a sensitivity analysis are presented in Section 5. Section 6 concludes.

\footnotetext{
${ }^{1}$ Other papers less related to our work consider the inequality-emissions relationship for small groups of industrialized countries. Magnani (2000) uses public expenditure for environmental protection as the dependent variable, and uses only 17-52 observations for developed countries. Marsiliani and Renstrom (2003) use sulfur, nitrogen and carbon dioxide and a different inequality measure: ratio of households ranked at top 90th percentile to the median household and two panels of 7 and 10 industrialized countries over 1978-97.
} 


\begin{tabular}{|c|c|c|c|}
\hline Argument & Basis & Sign & Reference \\
\hline \multirow[t]{3}{*}{ Political economy } & $\begin{array}{l}\text { Cost-benefit power-weighted } \\
\text { decision rule }\end{array}$ & Positive & Boyce (1994) \\
\hline & Cooperation & Positive & $\begin{array}{l}\text { Marsiliani and } \\
\quad \text { Renstrom (2003) }\end{array}$ \\
\hline & Voting for pollution policy & Ambiguous & $\begin{array}{l}\text { McAusland (2003) and } \\
\text { Gassebner et al. (2008) }\end{array}$ \\
\hline Variable MPE & Higher MPE for the rich & Negative & $\begin{array}{l}\text { Ravallion et al. (2000) and } \\
\text { Heerink et al. (2001) }\end{array}$ \\
\hline Emulation & Conspicuous consumption & Positive & Veblen (1899) \\
\hline
\end{tabular}

Table 1: Summary of theoretical arguments in the literature, and the implied sign for the correlation between income inequality and emissions.

\section{Theory}

Starting in the mid-1990's, economists have developed several theoretical arguments to explain the relationship between economic inequality and environmental degradation. While some of the arguments entail a positive association, namely the "equality hypothesis" proposed by Boyce (1994), Torras and Boyce (1998) and Borghesi (2006), others argue that greater inequality could also be negatively associated to emissions (Heerink et al. 2001; Ravallion et al. 2000; Scruggs 1998). If the second argument prevails, there will be a tradeoff between redistribution policies and environmental quality. Table 1 presents a list of the main theoretical arguments discussed in the previous literature.

Boyce (1994) proposes that greater inequality could increase environmental degradation via the impact on the rate of time preference and via a cost-benefit analysis. Boyce (1994) and Torras and Boyce (1998) assume that environmental quality is a public good and effective demand requires public policy solutions to this market failure. The factors they point out, already mentioned by Grossman and Krueger (1995), which allow economies to redress market failure more efficiently are "vigilance and advocacy". These two factors increase with per capita income because individuals gain greater power to make their demand effective through the political process. In particular, some individuals benefit from economic activities that generate pollution, whereas other citizens, adversely affected by pollution, bear net cost. The latter exercise vigilance and are in charge to demand for environmental controls, whereas the former attempt to prevent that those environmental 
controls are established or strengthened. Assuming that in more unequal societies those who benefit from pollution are more powerful than those who bear the cost, the benefit-cost rule will lead to predict an inefficient high level of pollution. This implies a positive correlation between income inequality and pollution. A controversial assumption they made to reach this outcome is that net benefit from polluting activities is positively correlated with individual income. However, Scruggs (1998) claims that wealthy and powerful individuals do not necessarily prefer more degradation than the rest and he also questions Boyce's underlying assumption that more democratic societies produce better environmental results than other political regimes. Also, it is unclear whether this argument, which has been formulated for environmental degradation more generally, also holds for carbon emissions. In the case of carbon emissions, costs are not only felt locally but globally and emission control is a global public good, where it is unclear that national income ineuqality will necesarily play a criticial role in this meachnism.

In the same line of reasoning as Boyce (1994), Borghesi (2006) suggests that an increase in inequality hinders the way for public policy solutions to environmental problems and therefore greater inequality can contribute to increasing emissions. Also Marsiliani and Renström (2003) argue that higher inequality leads to less environmental protection and consequently higher emissions in an overlapping generations model with a majority elected representative. The author points to the anecdotal evidence that Scandinavian countries are the most protective of their environment among the developed countries, being as well the most egalitarian. A different argument is put forward by McAusland (2003) and Gassebner et al. (2008). Both suggest that inequality may influence emissions through the channel of factor ownership and voting. According to McAusland (2003) the relationship between income inequality and demand for pollution policy depends on the level of ownership concentration and openness to trade in countries. Hence, empirical tests of the relationship between income inequality and environmental quality are expected to yield ambiguous results. The author suggests controlling for the source of income inequality in each country as well as for the endogenous price effects of its pollution policy.

Gassebener et al. similarly argue that, at least in richer countries, rising income inequality is associated with accelerated industrial decline (through increasing outsourcing of industrial produc- 
tion as well as skill-biased technical change), which in turn reduces the political power of industrial producers and workers, thereby reducing their ability to bloc measures to reduce pollution or emissions. Extending this line of argument, one could imagine that in poorer countries, the political clout of the rising industrial sector is rising as well, leading to less environmental regulation, particularly when richer population groups are associated with the rising industrial sector. Thus this line of argument could predict a different correlation between income inequality and empissions in poor and rich countries.

While these studies generally suggest that increasing income inequality will increase emissions, a second group of studies predicts exactly the opposite. Ravallion et al. (2000) point out that in a simple model where the marginal propensity to emit (MPE) varies with income, inequality measures enter the income-emission relationship, a point also made by Heerink et al. (2001) In fact, they point out that there will be a biased estimate in the income-emission relationship if income inequality is not included in the estimation. There is considerable evidence from micro studies in several countries that the MPE does indeed vary with the level of income, with most studies finding that the MPE falls with income (see Holtz-Eakin and Selden, 1995; Heil and Selden, 1999; Grunewald et al., 2012; Steckel et al., 2014; Serino and Klasen, 2015). This would imply that higher inequality would reduce emissions. This could be even more the case if, particularly in poorer countries, higher inequality would imply that a large share of the population essentially lives outside the carbon economy, i.e. they lack access to electricity and other forms of modern energy. For them the MPE might be close to 0; thus increasing their share in the populaion would lower aggregate emissions.

Finally, based on the "emulation theory" originally due to Veblen (1899), we hypothesize that in more unequal societies individuals in a given social class tend to compare themselves with the members of the immediately superior social class and emulate their consumption patterns. In this way, more unequal societies might have a higher propensity to consume more polluting intensive goods and services (such as big cars, long-distrance vacations, etc.) that are associated to a higher MPE and therefore to higher emissions in comparison to egalitarian societies.

In summary, the theoretical literature is ambiguous about the sign of the relationship between 
inequality and emissions that is conditioned to a number of underlying assumptions. In this respect, we aim to contribute with an empirical approach to shed light on some of the abovementioned theories. The contrasting theoretical arguments also suggest that the relationship is probably heterogeneous across countries, leading to different levels of emissions across countries, as well as to differences in income and inequality elasticities. In fact, it appears that some theories seem to suggest that high inequality is associated with more emissions in richer countries, while the relationship might be the reverse in poorer countries. Our specification below will enable us to examine such a non-monotonic relationship.

\section{Data}

We use an unbalanced panel data set with annual measurements from 1980 to 2008, covering 158 countries. The total number of observations is 3966. This data set is much more extensive than those used in the existing literature on the relationship between income inequality, GDP, and carbon emissions. The corner stone of our data set are the Gini coefficients from the Standardized World Income Inequality Database (SWIID) by Solt (2009). For the SWIID, a missing data algorithm was used to fill in the Gini measurements and to make the data from different sources comparable. Solt (2009) differentiates between before and after tax income inequality. Many high income countries apply strong redistributive policies, which lead to overall lower after-tax income inequality than before tax income inequality. We use after-tax income inequality measure because we are interested in the effect of redistributive policies, and want to account for those already in place.

The data on carbon dioxide emissions are from the Oak Ridge National Laboratory data set, which covers emissions from fossil fuel, natural gas consumption, and cement manufacturing (Boden et al. 2012). This data set is widely used in the literature but faces two major shortcomings, see e.g. Borghesi (2006). First, it is estimated data which is based on the consumption of fossil fuels multiplied with the average carbon content of the respective fuel type. Second, it does not account for emissions from agriculture, life stock, deforestation or land use change. Therefore, it will underestimate the carbon dioxide emissions for countries with a strong agricultural sector. 


\begin{tabular}{lllrrrr}
\hline Variable & Source & Unit & Mean & SD & Min & Max \\
\hline Main variables & & & & & & \\
$\mathrm{CO}_{2}$ emissions / capita & ORNL & metric tons & 3.79 & 4.66 & $<0.01$ & 35.2 \\
GDP per capita & WDI & mln 1990 \$ & 8879 & 10254 & 150.8 & 72783 \\
Gini & SWIID & percentage scale & 37.73 & 10.29 & 15.05 & 71.33 \\
\hline & & & & & & \\
Controls & & & & & & \\
Agriculture, value added & WDI & \% of GDP & 18.92 & 15.16 & 0.06 & 93.98 \\
Manufacturing, value added & WDI & \% of GDP & 15.91 & 7.91 & 0.36 & 46.25 \\
Services, etc., value added & WDI & \% of GDP & 51.06 & 13.50 & 3.67 & 92.24 \\
Urban population & WDI & \% of population & 50.70 & 23.05 & 4.08 & 100 \\
Polity & CSP & - & 2.59 & 6.95 & -10.00 & 10.00 \\
\hline
\end{tabular}

Table 2: Summary statistics for our unbalanced panel data set $(n=158, T \in\{1980, \cdots, 2008\})$. Total number of observations is 3966 .

But as shown in the recent IPCC report (IPCC, 2014), our data data cover about $75 \%$ of total GHG emissions (when expressed in CO2 equivalents) and this share is fairly stable over time.

GDP per capita and further control variables are taken from the World Development Indicators, see World Bank (2012). The measure of GDP that we use is based on purchasing power parity, and measured in constant 2005 International Dollars. The WDI also supplies the shares of value added of agriculture, manufacturing and the service sector in percentages of total GDP, and the proportion of the population that lives in cities ("Urban population"). Finally, we use the Polity measure, see Marshall and Cole (2011), which is a measure of state fragility that ranges from +10 (strongly democratic) to -10 (strongly autocratic). An overview of the variables, with summary statistics, are given in Table 2.

\section{Econometric model}

This section describes the fixed effects model and the group fixed effects model, which we use to investigate empirically the relationship between emissions, GDP, and income inequality. We emphasize that the group fixed effects estimator, proposed by Bonhomme and Manresa (2015), is an attractive alternative to the commonly used fixed effects estimator. The results for both models are described in Section 5 .

For country $i$ at time $t$, let $e_{i t}$ be $\log \mathrm{CO}_{2}$ emissions per capita, and let $y_{i t}$ denote log GDP per 
capita. Furthermore, let $g_{i t}$ denote the log of the Gini coefficient, which is our preferred measure of income inequality. Additional explanatory variables are collected in a vector $X_{i t}$. A useful starting point for our analysis is the following fixed effects model:

$$
e_{i t}=\alpha_{i}+\lambda_{t}+\beta_{1} y_{i t}+\beta_{2} y_{i t}^{2}+\beta_{3} g_{i t}+\beta_{4} y_{i t} g_{i t}+X_{i t} \gamma+u_{i t}
$$

with the standard assumptions on the error term $u_{i t}$, and allowing for an unrestricted relationship between the country- and time-specific effects $\left(\alpha_{i}, \lambda_{t}\right)$ and the covariates ("fixed effects"). The quadratic specification in $\left(y_{i t}, g_{i t}\right)$ serves as an approximation to a general, nonlinear relationship between emissions, GDP, and income inequality. The squared income inequality term is omitted, as it is highly correlated with $g_{i t}$, and our results are not sensitive to its omission.

Note that the quadratic income term allows the relationship between emissions and income to be non-monotonic. For example, it allows for the inverted $\mathrm{U}$ shape that is documented in the literature on the environmental Kuznets curve. The interaction term between income and inequality allows the relationship between income inequality and emissions to depend on income. In particular, we are interested in the elasticity of emissions per capita with respect to income inequality, which in this case is given by

$$
\eta \equiv \frac{\% \Delta E_{i t}}{\% \Delta G_{i t}} \approx \beta_{3}+\beta_{4} y_{i t}
$$

This elasticity depends on the current level of GDP per capita. For example, if $\beta_{3}<0$ and $\beta_{4}>0$, the elasticity is positive only if a country is rich enough, i.e. $y_{i t}>y^{*}=-\beta_{3} / \beta_{4}$ :

Models such as (1) are widely used in economics, and in the existing empirical papers on the relationship between income inequality and emissions. In particular, Ravallion et al. (2000) ignore heterogeneity, but allow for a cubic income term. Their omission of country-specific fixed effects is rejected by our empirical results. Borghesi (2006) uses a fixed effects model, but leaves out the interaction term between income and inequality. A further difference between the approach in Borghesi (2006) and our fixed effects approach is that we use a more extensive, higher quality data set. 
The fixed effects model (1) provides a flexible way to control for unobserved heterogeneity at the country level. A drawback is that the time effect $\lambda_{t}$ is restricted to be the same for all countries. Bonhomme and Manresa (2015) provide a useful alternative with their group fixed effects (GFE) model. Assume that we can categorize countries in a number of groups, indexed by $j=1, \cdots, J$. The number of groups $j$ must be small compared to the number of countries. Denote by $j(i)$ the group that country $i$ belongs to. An estimator is proposed for the parameters in

$$
e_{i t}=\alpha_{j(i), t}+\beta_{1} y_{i t}+\beta_{2} y_{i t}^{2}+\beta_{3} g_{i t}+\beta_{4} y_{i t} g_{i t}+X_{i t} \gamma+u_{i t},
$$

without requiring the researcher to specify $j(i)$. Rather than deciding on group membership before the analysis, it is estimated along with the other parameters in this model. Group membership dummies and regression coefficient are jointly estimated by minimizing the sum of squares of residuals. Restrictions on the error term $u_{i t}$ are not meaningfully different from those in model (1).

The most important difference between the fixed effects and GFE models is the restriction on the evolution of unobserved heterogeneity. The fixed effects model allows for an effect $\alpha_{i t}=\alpha_{i}+\lambda_{t}$ for country $i$ at time $t$, which restricts all countries to have the same pattern over time. In contrast, the GFE model allows for an effect $\alpha_{i t}=\alpha_{j(i), t}$, restricting the pattern to be the same for all countries within a group, but allowing different groups to have fully distinct patterns. Note that these two models are not nested.

For our setting, the GFE model is an attractive alternative to the fixed effects model. To see this, we temporarily abstract from our nonlinear world and from the influence of income inequality and consider a very simple relationship between GDP per capita $\left(Y_{i t}\right)$ and carbon emissions per capita $\left(E_{i t}\right)$, see e.g. Ikefuji et al. (2014):

$$
E_{i t}=\sigma_{i t}\left(1-\mu_{i t}\right) Y_{i t}
$$

where $\sigma_{i t}$ and $\mu_{i t}$ are the emissions-to-output ratio and abatement factors for country $i$ at time $t$. The emissions-to-output ratio $\sigma_{i t}$ can be seen as a technology parameter that measures the extent 
to which clean technology is used in the economy, or the average carbon intensity of the technology used in production. In this simple model, we would have

$$
\begin{aligned}
e_{i t} & =\log \sigma_{i t}+\log \left(1-\mu_{i t}\right)+y_{i t} \\
& =\alpha_{i t}+y_{i t} .
\end{aligned}
$$

Using a standard fixed effects model with time dummies restricts

$$
\log \sigma_{i t}+\log \left(1-\mu_{i t}\right)=\alpha_{i}+\lambda_{t}
$$

which requires that the changes in emissions-to-output ratio and abatement policies are the same for all countries. This does not seem plausible, and is not in line with assumptions of climate-economy models. For example, when calibrating his DICE model, Nordhaus (2010) writes: "Technological change is projected for a frontier region (the United States), and other countries are assumed to converge partway to the frontier." This is not consistent with the fixed effects specification. The GFE model, on the other hand, assumes that the world can be divided into several regions who have similar trends in these unobservables.

There are two further advantages of the GFE estimator. First, the time-varying group fixed effects are arguably better suited to deal with endogeneity due to unobserved time-varying heterogeneity. Second, since the intertemporal variation in the Gini is relatively small compared to the cross-country variation, the fixed effects estimator would take out a large share of the betweencountry variation. We refer to the debate on the inequality and growth, see e.g. Forbes (2000) and Banerjee and Duflo (2003).

\section{$5 \quad$ Results}

This section presents the results of our empirical analysis. It describes and reports on two benchmark models, and then performs a sensitivity analysis. Our main finding is that, below a certain level of GDP per capita, there is a negative relationship between income inequality and per capita 


\begin{tabular}{|c|c|c|c|}
\hline & OLS & $\mathrm{FE}$ & GFE \\
\hline \multicolumn{4}{|l|}{ Parameters } \\
\hline$y_{i t}$ & $\begin{array}{r}2.76 * * * \\
(0.27)\end{array}$ & $\begin{array}{r}2.72^{* * *} \\
(0.93)\end{array}$ & $\begin{array}{r}3.29^{* * *} \\
(0.27)\end{array}$ \\
\hline$y_{i t}^{2}$ & $\begin{array}{r}-0.18^{* * *} \\
(0.01)\end{array}$ & $\begin{array}{r}-0.15^{* * *} \\
(0.04)\end{array}$ & $\begin{array}{r}-0.18^{* * *} \\
(0.01)\end{array}$ \\
\hline$g_{i t}$ & $\begin{array}{r}-4.35^{* * *} \\
(0.41)\end{array}$ & $\begin{array}{r}-1.18 \\
(1.14)\end{array}$ & $\begin{array}{r}-2.20^{* * *} \\
(0.43)\end{array}$ \\
\hline$y_{i t} g_{i t}$ & $\begin{array}{r}0.38^{* * *} \\
(0.05) \\
\end{array}$ & $\begin{array}{r}0.13 \\
(0.13) \\
\end{array}$ & $\begin{array}{r}0.24^{* * * *} \\
(0.05) \\
\end{array}$ \\
\hline Emission-inequality & elasticity & & \\
\hline U.S. $(2005)$ & -0.31 & 0.21 & 0.35 \\
\hline India (2005) & -1.42 & -0.17 & -0.35 \\
\hline Threshold, $y^{*}$ & 11.45 & 9.02 & 9.17 \\
\hline Country effects & No & Yes & Group \\
\hline Year effects & Yes & Yes & Group \\
\hline Number of groups & - & - & 5 \\
\hline Observations & 2939 & 2939 & 2937 \\
\hline$R^{2}$ & 0.85 & 0.98 & 0.97 \\
\hline
\end{tabular}

Table 3: Parameter estimates for the benchmark model. Dependent variable: log of per capita carbon dioxide emissions, $e_{i t}$. Robust standard errors in parentheses. ${ }^{*} p<0.1,{ }^{* *} p<0.05,{ }^{* * *} p<0.01$.

emissions. This suggests that, for low income countries, lowering inequality will result in higher levels of carbon emissions. For richer countries, reductions in income inequality will simultaneously cause emissions to decrease.

Table 3 reports the coefficients for our benchmark models, which do not include variables other than income and income inequality. The first column contains the results from ordinary least squares (OLS). The second and the third present the results from the fixed effects and grouped fixed effects model, respectively. The group fixed effects model uses five groups, based on informal investigation of the change in the criterion function.

Several findings are worth reporting. First, in all models, we find that the relationship between income inequality and emissions depends on the level of GDP per capita, i.e. the coefficient of the interaction term is positive in all specifications and statistically significant in the OLS and the group fixed effects estimator. In particular, in all models, a country has to be above a certain threshold income for the elasticity between emissions and income inequality to become positive. 


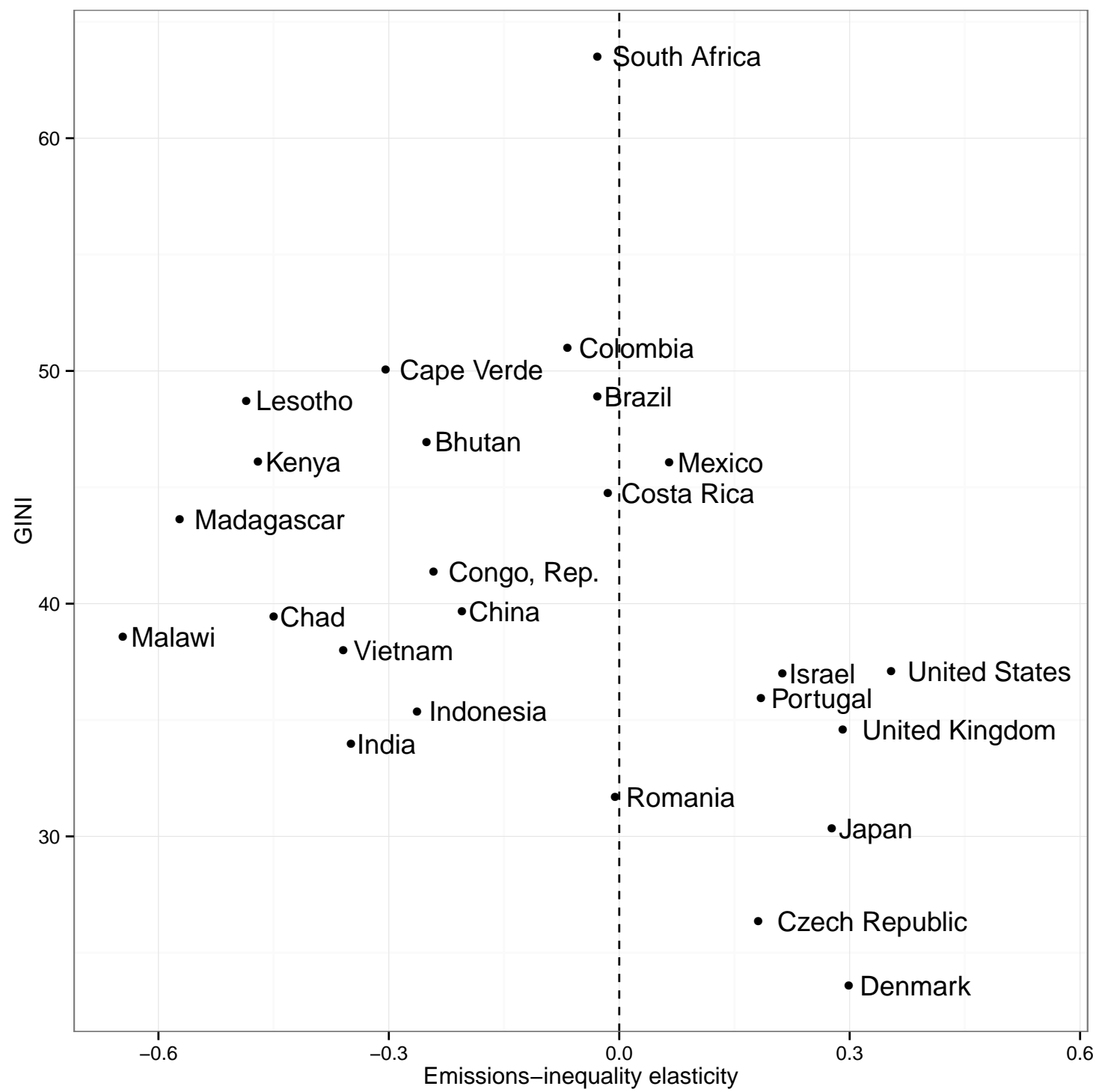

Figure 1: Estimated emission-inequality elasticities for a group of countries in 2005, for the benchmark grouped fixed effects model. 
For the fixed effects and group fixed effects model, threshold income $y^{*}$ is in-sample and around the income levels of upper middle income countries such as Mexico, Brazil, Romania or South Africa ( $\$ 8290$ and $\$ 9573)$. Figure 1 displays a range of estimated elasticities for an arbitrary set of countries in 2005 for the group fixed effects model. This demonstrates our key finding: lowering inequality will be good for the environment and decrease carbon dioxide levels in countries above a certain income threshold of GDP per capita.

Second, the three models yield quite different results for the estimated elasticities. The OLS estimate for the threshold $y^{*}$ is out-of-sample, and the estimated elasticity for the US in 2005 is negative. For India in 2005, the emission-inequality relationship is strongly negative and, with an elasticity of 1.42, highly elastic. This deviates from the finding of the panel data estimators, who find an in-sample turning point. The relatively poor fit of the OLS regression leads us to reject the absence of heterogeneity. A Hausman test rejects the random effects specification at the $1 \%$ level. Third, in all models, we find an inverted-U relationship between carbon dioxide emissions and income, in accordance with the literature on the environmental Kuznets curve (EKC).

Fourth, the groups and their time trends, as estimated by the group fixed effects estimator, can be meaningfully interpreted. The groups are described in Table 4 and the estimated time trends are depicted in Figure 2. Group membership can be characterized by differences in the energy intensity (EI) and its evolution over time. On the one hand, groups 1 and 2 contain countries with high levels of EI over the period (0.62 and $1.17 \mathrm{Kg} / \$ 1000 \mathrm{US} \$)$, whereas countries in groups 4 and 5 have a relatively low average EI (0.32 and 0.23). Group 3 includes countries with the lowest average EI (0.17). On the other hand, the levels of EI have been drastically reduced in group 2, moderately reduced in groups 1, 4 and 5 and remain fairly stable in group 3. More specifically, group 3 contains countries mainly located in Latin America and Africa. Some of these are resource-abundant countries, e.g. Brazil and Costa Rica, and have been very active in the recent past in terms of environmental policies. Most EU countries are in groups 4 and 5, which are the biggest groups. Group 2 contains only 8 countries, which are all located in Central Europe and Asia and are characterized by very high levels of EI in the 1990s, which experienced drastic reductions in the $1990 \mathrm{~s}$ and $2000 \mathrm{~s}$. 


\begin{tabular}{|c|c|c|c|}
\hline Group 1 & Group 3 & Group 4 & Group 5 \\
\hline Australia & Albania & Algeria & Angola \\
\hline Belarus & Botswana & Armenia & Argentina \\
\hline Bosnia and Herzegovina & Brazil & Bangladesh & Austria \\
\hline Bulgaria & Burkina Faso & Belgium & Belize \\
\hline Canada & Cameroon & Benin & Bolivia \\
\hline Czech Republic & Cape Verde & Burundi & Cambodia \\
\hline Estonia & Chad & Cyprus & Central African Republic \\
\hline Guinea-Bissau & Colombia & Denmark & Chile \\
\hline Guyana & Costa Rica & Egypt, Arab Rep. & Comoros \\
\hline India & El Salvador & Finland & Cote d'Ivoire \\
\hline Jordan & Gabon & Georgia & Croatia \\
\hline Kyrgyz Republic & Guatemala & Germany & Djibouti \\
\hline Luxembourg & Haiti & Ghana & Dominican Republic \\
\hline Macedonia, FYR & Lao PDR & Greece & Ecuador \\
\hline Mauritania & Madagascar & Hungary & Ethiopia \\
\hline Poland & Mali & Indonesia & Fiji \\
\hline Russian Federation & Mauritius & Iran, Islamic Rep. & France \\
\hline Sierra Leone & Namibia & Ireland & Gambia, The \\
\hline South Africa & Nepal & Israel & Guinea \\
\hline Suriname & Panama & Jamaica & Honduras \\
\hline Trinidad and Tobago & Paraguay & Japan & Hong Kong, China \\
\hline \multirow[t]{2}{*}{ United States } & Peru & Korea, Rep. & Iceland \\
\hline & Sri Lanka & Malaysia & Italy \\
\hline Group 2 & St. Lucia & Mozambique & Kenya \\
\hline Azerbaijan & Swaziland & Netherlands & Latvia \\
\hline China & Tanzania & Nicaragua & Lithuania \\
\hline Kazakhstan & Uganda & Niger & Malawi \\
\hline Moldova & Uruguay & Nigeria & Malta \\
\hline Mongolia & & Pakistan & Mexico \\
\hline Turkmenistan & & Romania & Morocco \\
\hline Ukraine & & Senegal & New Zealand \\
\hline \multirow[t]{10}{*}{ Uzbekistan } & & Singapore & Norway \\
\hline & & Slovak Republic & Papua New Guinea \\
\hline & & Slovenia & Philippines \\
\hline & & Tajikistan & Portugal \\
\hline & & Thailand & Rwanda \\
\hline & & United Kingdom & Spain \\
\hline & & Venezuela, RB & Sweden \\
\hline & & Vietnam & Switzerland \\
\hline & & Yemen, Rep. & Tunisia \\
\hline & & Zambia & Turkey \\
\hline
\end{tabular}

Table 4: Estimated grouping for the group fixed effects estimator, five groups. 


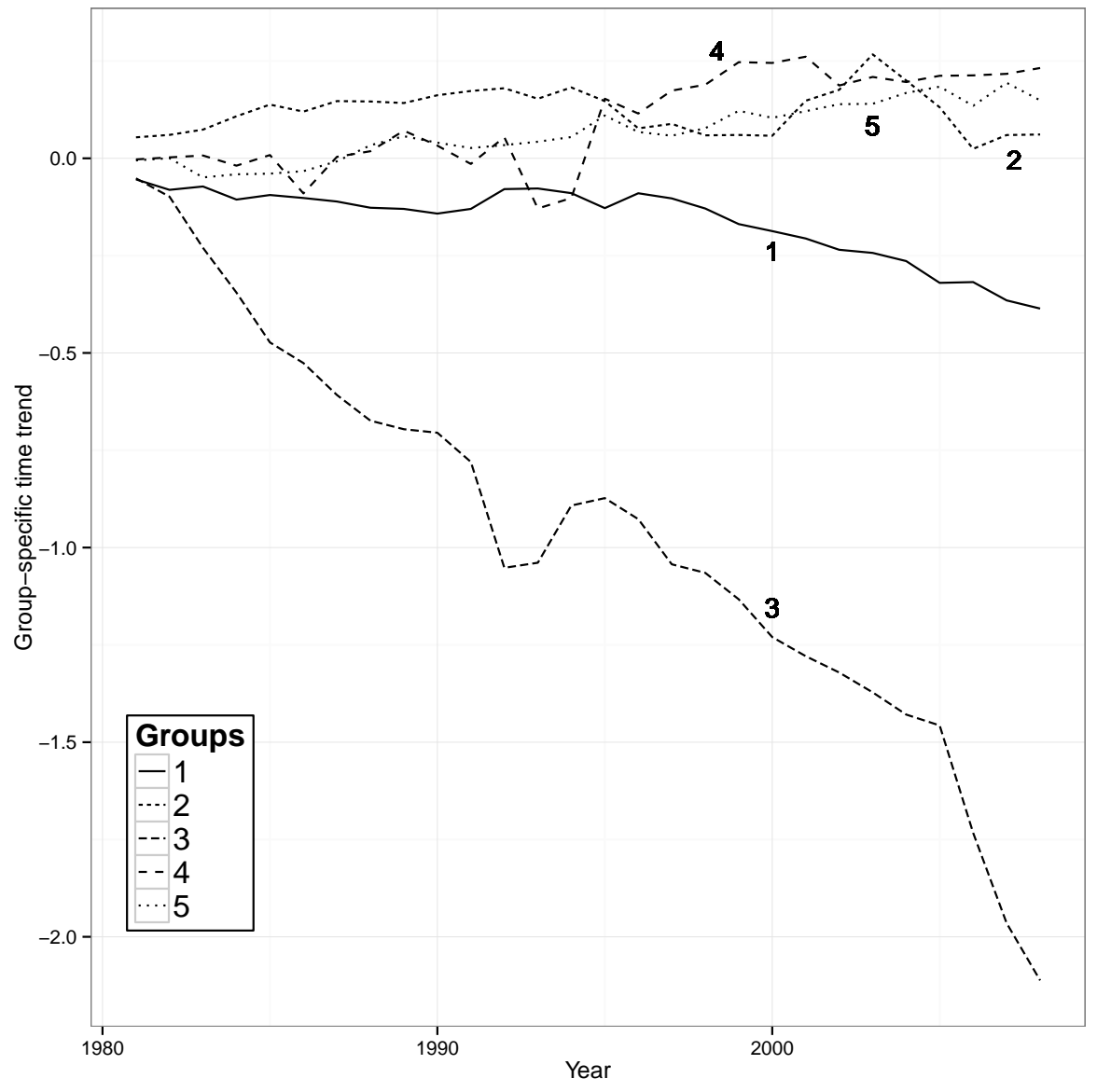

Figure 2: Estimated time trends for each group. The time trends are normalized such that they have an average of zero. 


\begin{tabular}{lrrr}
\hline & 3-year & Polity & Channels \\
\hline Parameters & & & \\
$y_{i t}$ & $4.02^{* * *}$ & $3.36^{* * *}$ & $1.55^{* * *}$ \\
& $(0.24)$ & $(0.26)$ & $(0.31)$ \\
$y_{i t}^{2}$ & $-0.18^{* * *}$ & $-0.18^{* * *}$ & $-0.07^{* * *}$ \\
& $(0.01)$ & $(0.01)$ & $(0.01)$ \\
$g_{i t}$ & $-1.05^{* * *}$ & $-2.15^{* * *}$ & $-1.82^{* * *}$ \\
& $(0.30)$ & $(0.43)$ & $(0.57)$ \\
$y_{i t} g_{i t}$ & 0.04 & $0.24^{* * *}$ & $0.13^{* *}$ \\
& $(0.03)$ & $(0.05)$ & $(0.06)$ \\
& & & \\
Emissions-inequality & elasticity & & \\
U.S. (2005) & -0.64 & 0.35 & -0.43 \\
India (2005) & -0.75 & -0.33 & -0.81 \\
Threshold $y^{*}$ & 27.6 & 9.13 & 13.9 \\
& & & \\
Country effects & Group & Group & Group \\
Year effects & Yes & Yes & Yes \\
Number of groups & 5 & 5 & 5 \\
Observations & 1279 & 2752 & 2270 \\
\hline
\end{tabular}

Table 5: Sensitivity analysis. For a detailed description of the specification for each column, see text. Robust standard errors in parentheses. ${ }^{*} p<0.1,{ }^{* *} p<0.05,{ }^{* * *} p<0.01$.

Sensitivity analysis. We perform robustness checks in several directions. We report some of the results in Table 5. We considered many other robustness checks: different number of groups; different GINI measures (from Gruen and Klasen, 2008); different time periods, etc. The results from these models do not change our main findings. The starting point for the sensitivity analysis is the group fixed effects estimator. First, we estimate the model with data averaged to 3-year averages (Table 5, first column). This reduces the unbalancedness of the data, and checks that our results are not driven by short-run fluctuations. Note that our main findings are unchanged: (i) the sign of the emission-inequality elasticity is negative at low values of income, and positive for a sufficiently rich country; (ii) there is an inverted-U shaped relationship between income and carbon emissions. However, the threshold value of income is out of sample, so that both reported estimated elasticities are negative. This could be due to lack of precision because of the reduced sample size, see for example the relatively high standard error of the interaction term.

Second, we investigate whether the relationship holds even if we include some plausible transmission channels. In particular, we control for the quality of institutions that could be a proxy 
for environmental regulations by including the Polity measure (Table 5, column "Polity"). We also control for other transmission channels by including as additional variables the share of population living in cities, and the shares of agriculture, manufacturing, and services (Table 5, column "Channels"). None of these robustness checks change our conclusions. This suggests that the income-contingent effect of inequality on emissions persists beyond these plausible transmission channels.

Third, we estimate a fixed effects model using the data set described in Gruen and Klasen (2008), which is based on the World Income Inequality Database (WIID). The adjustments done by Gruen and Klasen (2008) use a regression-based method to deal hamronize the income and income unit concepts used in the different data points in WIID. The results are reported in Appendix A, Table 6. We find that the results are not driven by the choice of WIID versus SWIID (the data set used for our main results). At the same time, SWIID provides us with a substantially larger number of observations. The small number of observations in WIID is problematic when we try to estimate the group fixed effects model. Therefore, although there are some conceptual advantages of WIID over SWIID (see Jenkins, 2014), the advantages of SWIID dominate those for our purposes.

\section{Conclusion}

Based on a substantially larger data set (in both regional and temporal coverage) than the existing literature, we investigate the theoretically ambiguous link between income inequality and emissions. We find that the relationship depends on the level of income. Using an arguably superior groupfixed effects estimator, we show that for low and middle-income economies, higher income inequality is associated with lower carbon emissions while in upper middle-income and high-income economies, higher income inequality increases per capita emissions. The result is robust to the inclusion of plausible transmission variables as well as different data sources or aggregations. Our paper also illustrates the usefulness of the group fixed effects estimator which helps to address some of the short-comings in standard panel econometric approaches to this question.

With regard to the theoretical literature discussed above, it may be the case that in poor 
countries, the claims made by Ravallion et al. (2000) and Heerink et al. (2001) are particularly pertinent. In highly unequal poor societies a large share of the population lives essentially outside of the carbon economy and produces few emissions while the very rich already have lower marginal propensities to emit than middle income groups which is consistent with micro-level estimations of carbon footprints (e.g. Grunewald et al. 2011; Serino and Klasen, 2015); in contrast in richer economies, the political economy mechanisms proposed in the literature may be at work where in more equal societies, it is easier to arrive at a social consensus on environmental policies and the relative power of groups that benefit from emissions (e.g. owners of capital) is weaker. More research is required to better understand the drivers of this income contingent empirical relationship.

These findings are also quite important for policy. While for richer countries, the reduction of inequality can facilitiate reductions in emissions, in poorer countries there is a clear trade-off. That trade-off can only be addressed if one can ensure that higher incomes of poorer population groups do not translate into higher emissions by, for example, ensuring that the higher energy needs are largely met by renewable energy technologies. (Maybe you can then refer again to Steckel et al. 2014, the Nature Climate Change Paper)

\section{References}

[1] Banerjee, AV, Duflo E (2003). "Inequality And Growth: What Can The Data Say?" Journal of Economic Growth, 8, 267-299.

[2] Boden TA, Marland G, Andres RJ (2012). Global, Regional, and National Fossil-Fuel CO2 Emissions. Carbon Dioxide Information Analysis Center, Oak Ridge National Laboratory, Oak Ridge, U.S.A.

[3] Bonhomme S, Manresa E (2015). "Grouped Patterns of Heterogeneity in Panel Data." Econometrica, forthcoming.

[4] Borghesi S (2006). "Income Inequality and the Environmental Kuznets Curve." In: Basili M, Franzini M, Vercelli A (eds), "Environment, Inequality and Collective Action," Routledge, London, U.K. 
[5] Bourguignon, F (2003). "The Growth Elasticity of Poverty Reduction." In: Eicher T, Turnovsky S (eds), "Inequality and Growth: Theory and Policy Implications," MIT Press, Cambridge, Mass.

[6] Boyce JK (1994). "Inequality as a Cause of Environmental Degradation." Ecological Economics, 11, 169-178.

[7] Deininger K, Squire L (1996). "A New Data Set Measuring Income Inequality." The World Bank Economic Review, 10, 565-591.

[8] Dollar D, Kraay A (2002). "Growth is Good for the Poor." Journal of Economic Growth, 7, $195-225$.

[9] Forbes, KJ (2000). "A Reassessment of the Relationship between Inequality and Growth." American Economic Review, 90, 869-887.

[10] Gassebner M, Gaston N, Lamla MJ (2008). "Relief for the Environment? The Importance of an Increasingly Unimportant Industrial Sector." Economic Inquiry, 46, 160-178.

[11] Grossman GM, Krueger AB (1995). "Economic Growth and the Environment." The Quarterly Journal of Economics, 110, 353-377.

[12] Gruen C, Klasen S (2008). "Growth, Inequality, and Welfare: Comparisons Across Space and Time." Oxford Economic Papers, 60, 212-236.

[13] xxx Grunewald et al. 2012

[14] Heerink N, Mulatu A, Bulte E (2001). "Income Inequality and the Environment: Aggregation Bias in Environmental Kuznets Curves." Ecological Economics, 38, 359-367.

[15] Heil MT, Selden TM (1999). "Panel Stationarity with Structural Breaks: Carbon Emissions and GDP." Applied Economics Letters, 6, 223-225.

[16] Holtz-Eakin D, Selden TM (1995). "Stoking the Fires? C02 Emissions and Economic Growth." Journal of Public Economics, 57, 85-101. 
[17] Ikefuji M, Laeven RJA, Magnus JR, Muris C (2014). "Expected Utility and Catastrophic Risk." Manuscript.

[18] IPCC (2014). Climate Change 2014: Mitigation of Climate Change. Contribution of Working Group III to the Fifth Assessment Report of the Intergovernmental Panel on Climate Change. Edenhofer O., Pichs-Madruga R, Sokona Y, Farahani E, Kadner S, Seyboth K, Adler A, Baum I, Brunner S, Eickemeier P, Kriemann B, Savolainen J, Schlömer S, von Stechow C, Zwickel T, Minx JC (eds.)]. Cambridge University Press, Cambridge, United Kingdom and New York, NY, USA.

[19] Jakob M, Steckel JC, Klasen S, Lay J, Grunewald N, Martinez-Zarzoso I, Renner S, Edenhofer O (2014). "Feasible Mitigation Actions in Developing Countries." Nature Climate Change, 4, 961-968.

[20] Jenkins SP (2014). "World Income Inequality Databses: An Assessment of WIID and SWIID." Working Paper 2014-31. Colchester: Institute for Social and Economic Research, University of Essex.

[21] Magnani E (2000). "The Environmental Kuznets Curve, Environmental Protection Policy and Income Distribution." Ecological Economics, 32, 431-443.

[22] Marshall MG, Cole BR (2011). Global report 2011. Conflict, Governance, and State Fragility. Center for Systemic Peace.

[23] Marsiliani L, Renström TI (2003). "Inequality, Environmental Protection and Growth." CEPR Discussion Paper 3754.

[24] McAusland C (2003). "Voting for Pollution Policy: The Importance of Income Inequality and Openness to Trade." Journal of International Economics, 61, 425-451.

[25] Nordhaus, W (2010). "Economic Aspects of Global Warming in a Post-Copenhagen Environment." Proceedings of the National Academy of Sciences, 107 (26), 11721-11726. 
[26] Ravallion M, Heil M, Jalan J (2000). "Carbon Emissions and Income Inequality." Oxford Economic papers, 52, 651-669.

[27] Scruggs LA (1998). "Political and Economic Inequality and the Environment." Ecological Economics, 26, 259-275.

[28] Serino MNV, Klasen S (2015). "Estimation and Determinants of the Philippines' Household Carbon Footprint", The Developing Economies, forthcoming.

[29] Solt F (2009). "Standardizing the World Income Inequality Database." Social Science Quarterly, 90, 231-242.

[30] Torras M, Boyce JK (1998). "Income, Inequality, and Pollution: A Reassessment of the Environmental Kuznets Curve." Ecological Economics, 25, 147-160.

[31] Veblen T (1899). The Theory of the Leisure Class: An Economic Study of Institutions. Macmillan, New York, U.S.

[32] World Bank (2012). World Development Indicators. http://data.worldbank.org/ data-catalog/. Accessed 29 Dec 2011.

\section{A Results using WIID}

This appendix reports the results of estimating the parameters in a fixed effects using two different data sets on income inequality. The second column ("Benchmark") in Table 6 corresponds to the fixed effect results reported in the text (Table 3, column FE). The first column estimates the same fixed effects model using the data set described in Gruen and Klasen (2008). 


\begin{tabular}{lrr}
\hline & Gruen and Klasen & Benchmark \\
\hline Parameters & & \\
$y_{i t}$ & $\left(0.99^{* *}\right.$ & $2.72^{* * *}$ \\
& $-0.12^{* * *}$ & $(0.93)$ \\
$y_{i t}^{2}$ & $(0.04)$ & $-0.15^{* * *}$ \\
& -0.788 & $(0.04)$ \\
$g_{i t}$ & $(1.04)$ & -1.18 \\
& 0.0611 & $0.14)$ \\
$y_{i t} g_{i t}$ & $(0.12)$ & $(0.13)$ \\
& &
\end{tabular}

Table 6: Parameter estimates for the benchmark model. Dependent variable: log of per capita carbon dioxide emissions, $e_{i t}$. Robust standard errors in parentheses. ${ }^{*} p<0.1,{ }^{* *} p<0.05,{ }^{* * *} p<0.01$. 